\section{Assessment of malaria reporting and epidemic preparedness systems in health facilities in Eldoret West District, Uasin Gishu County, Kenya}

\author{
Ruth C. Kirinyet, Arthur S. Ng'etich, \\ Ahmad Juma \\ Department of Epidemiology and \\ Biostatistics, School of Public Health, Moi \\ University, Kenya
}

\section{Abstract}

The most important factor in reducing the impact of an epidemic is a timely response with implementation of effective control measures at the point of detection. This study sought to assess the malaria reporting and epidemic preparedness systems of health facilities in Eldoret West District, Kenya. A crosssectional study design was adapted. A census technique was used to select all the forty five health facilities in the district comprising of government, mission and non-governmental facilities. An interviewer administered questionnaire was used for data collection and analysis done using Stata. Categorical variables were summarized as frequencies and corresponding percentages. The overall reporting rate was $91.7 \%$ for all the health facilities. Only 15 health facilities (33\%) plotted malaria trend lines for number of cases of malaria. Malaria epidemics were reported within 24 hours in 22 health facilities but they lacked the appropriate supplies to respond to confirmed cases or epidemics. The overall malaria reporting completeness rate was above $90 \%$ implying that the malaria surveillance system was generally good. Concerted efforts by concerned stakeholders should ensure improvement of malaria epidemic preparedness system in al health facilities and provision of information to health personnel on malaria outbreak response strategies.

\section{Introduction}

Recent estimates from World Health Organization (WHO) show that there were 214 million new cases of malaria worldwide in the year 2015. The African Region accounted for most global cases of malaria (88\%), followed by South-East Asia Region (10\%) and the Eastern Mediterranean Region (2\%). There were an estimated 438,000 malaria deaths worldwide with under-fives making up 306,000 death cases globally. Malaria has placed a heavy economic burden on health systems in Africa with the average annual cost of case management estimated at nearly 300 million US Dollars. ${ }^{1}$ Malaria surveillance is essential to guide program planning and management, inform governments and donors on progress towards malaria control, and assist with advocacy. Surveillance also provides the basis for the design, refinement and resource allocation of control programs. ${ }^{2}$ Periodic epidemics of malaria are a major public health problem for many sub-Saharan African countries. Populations in epidemic prone areas have a poorly developed immunity to malaria and the disease remains life threatening to all age groups. The impact of epidemics could be minimized by prediction and improved prevention through timely vector control and deployment of appropriate drugs. Malaria Early Warning Systems are advocated as a means of improving the opportunity for preparedness and timely response. ${ }^{3}$ In Kenya, malaria is one of the priority diseases for Integrated Disease Surveillance and Response (IDSR) and falls under the category of diseases of public health importance. The four pillars of disease surveillance include; epidemic preparedness and response, laboratory surveillance, data management and training and supervision. Malaria epidemics in Kenya occur in two malaria epidemiological zones - the western highlands and the arid, semi-arid lowlands of northern Kenya. The epidemics are associated with unusual climatic conditions especially rainfall accompanied by other factors like suitable temperatures that favor breeding and longer survival of the malaria vectors. ${ }^{4}$

Malaria poses an enormous health and economic burden in Kenya, being a leading cause of morbidity and mortality in the country. Recognizing this fact, the government of Kenya in consultation with local and international stakeholders undertook a comprehensive malaria program review which provided information leading to the development of the Kenya National Malaria Strategy (NMS) 20092017. ${ }^{4}$ The malaria surveillance and response system for the epidemic-prone districts, managed by the Division of Disease Surveillance and Response, is an important part of Kenya's 2009-2017 monitoring and evaluation plan. Epidemic thresholds for malaria have been set for four to six sentinel facilities in each of these districts. ${ }^{5}$

President's Malaria Initiative (PMI) has supported the Division of Malaria Control (DOMC) and the Division of Disease Surveillance and Response (DDSR) in PMIsupported districts to establish these thresholds and to make use of data collated locally for planning. Health centers submit data to districts on a weekly basis, and districts then transmit the data to provincial and national
Correspondence: Saitabau Arthur Ng'etich, Department of Epidemiology and Biostatistics, School of Public Health, Moi University, P.O. Box 7470-30100, Eldoret, Kenya.

Tel.: +254.710.890.400.

E-mail: arthursaitabau@yahoo.com

Key words: Malaria; Diagnosis; Treatment; Practices; Kenya

Acknowledgements: The authors would like to thank their university academic professors for their mentorship and invaluable advice that has greatly contributed to the success of this research. We appreciate the support, cooperation and the information received from the DDSC (District Disease Surveillance Coordinator), DMCC (District Malaria Control Coordinator) and DPHO (District Public Health Officer) and all the staff of the health facilities visited in Eldoret West District. Lastly, the invaluable contribution of all study participants without whom this research would not be possible.

Contributions: RCK, research idea conception, study designing, data collection, analysis, and interpretation of data, references, drafting and revising the manuscript and final review and approval of final version of manuscript for publication; ASN, interpretation of manuscript, revising manuscript and final approval of version to be published; AJ, references and revising manuscript and final approval of version for publication.

Conflict of interests: the authors declare no potential conflict of interests.

Dedication: this research study is dedicated to the health facilities and the entire community of Eldoret West District, Uasin Gishu County.

Received for publication: 4 April 2016.

Revision received: 18 August 2016.

Accepted for publication: 31 August 2016.

This work is licensed under a Creative Commons Attribution NonCommercial 4.0 License (CC BYNC 4.0).

(C) Copyright R.C. Kirinyet et al., 2016

Licensee PAGEPress, Italy

Journal of Public Health in Africa 2016; 7:549

doi:10.4081/jphia.2016.549

level by text message. Data is reviewed at the district level and case counts above preset thresholds are investigated by the district health officer. ${ }^{5}$ Data published by WHO World Malaria report 2011 showed that in Kenya, completeness of reporting was at $40 \%$ therefore much needed to be done to achieve the recommended target of $100 \%{ }^{6}$ Since the year 2000 , major epidemics have been observed in the malaria epidemic prone districts. Malaria epidemics are some of the most serious public 
health emergencies with which health officials have to deal with. ${ }^{4}$ Typically, they occur with little or no warning and in areas where the health system is often unprepared to deal with the problem. In most situations epidemic conditions take some weeks to build up, theoretically allowing time for preventive action. Even when an epidemic occurs, it takes several weeks to reach its peak, so that some effective control is possible if implemented in the early stages of development. The longer an epidemic goes undetected with no measures for its control, the higher the costs in terms of morbidity and mortality. ${ }^{7}$ This study focused on malaria reporting and epidemic preparedness systems. The main weakness of the systems are the incompleteness, delays and poor quality of routine surveillance data made available through the Health Management Information Systems (HMIS) and this was evident in health facilities in Eldoret West District. ${ }^{5}$ There were no prior published studies done on malaria surveillance in health facilities in Eldoret West District. It is expected that the findings of the study will be useful to the District Health Management Team (DHMT), NonGovernmental Organizations (NGO's), Ministry of Health (MOH), community and other stakeholders to come up with baseline data and intervention strategies which will bring about long lasting solution to the control of malaria in the district and form a basis for further studies. This research will also contribute to the field of knowledge and act as a resource material for future research.

\section{Materials and Methods}

\section{Study design and procedure}

The study area was Eldoret West District, Uasin Gishu County, Kenya. The study was conducted in the two divisions, Soy and Turbo divisions in the District. A cross sectional study design was adapted. A census study design was applied where all the forty five (45) health facilities in the district were included in the study and these comprised; government, mission, private and NGO.

\section{Data collection and analysis}

Survey questionnaires were used to collect information in the health facilities. Information was obtained from key health personnel (i.e. malaria outbreak coordinators) to fill up the health facility survey questionnaires. A checklist for recording completeness of reporting from the health facility to the District was also administered. The checklist had the name of the various health facilities and the malaria reporting by month, total number of reports that arrived on time, total num- ber of expected reports and total number of reports not received.

The filled health facility survey questionnaires were checked for completeness and coded. Data was then entered in computerized Ms Access database and was later exported to Stata version 12 Special Edition (SE) for analysis. Categorical variables were summarized as frequencies and the corresponding percentages. Continuous variables were summarized as the median and the corresponding lower and upper quartiles.

\section{Ethical consideration}

The aim of the study was explained in detail to the various health personnel before gaining informed consent from them. All the information from respondents was treated with the utmost confidentiality it deserved. Respect and dignity was upheld while collecting data. An approval from the Institutional Research and Ethics Committee (IREC) of Moi University was obtained prior to the commencement of the study. Permission to conduct the study in the District was sought from the $\mathrm{DMOH}$ and DPHO and a formal letter was obtained.

\section{Results}

Proportion of health facilities in the district

A total of 45 health facilities were studied; 3 (7\%) were clinics, 24 (53\%) were dispen- saries, 2 (4\%) were hospitals and 16 (36\%) were health centers. Of these number, 23 (51\%) were from Turbo with 3 (13\%) clinics, $11(48 \%)$ dispensaries, 1 (4\%) hospital and 8 (35\%) health centers. The remaining 22 (49\%) health facilities were from Soy with 13 (59\%) dispensaries, 1 (5\%) hospital and 8 (36\%) health centers as shown in (Figure 1).

Government health facilities studied were $33(76 \%)$ where 20 (61\%) were dispensaries, $11(33 \%)$ were health centers and 2 (6\%) were hospitals. The rest 12 (24\%) health facilities were private, mission or non-governmental health facilities where 3 (25\%) were clinics, 4 (33\%) were dispensaries and 5 (42\%) were health centers as shown in (Figure 2).

\section{Plotting of malaria trend lines and maps for the cases of malaria}

Fifteen (33\%) health facilities plotted malaria trend lines for the number of cases of malaria. However, only 4 (9\%) health facilities plotted the distribution of malaria cases on a map. None of the 45 health facilities plotted malaria trend lines and map showing deaths due to malaria (Table 1).

\section{Malaria outbreak coordinators}

Thirty-four (76\%) health facilities had a coordinator such as Public Health Officer (PHO), Public Health Technician (PHT), Clinical Officer (CO) or Nurse as illustrated in Figure 3. Twenty two (56\%) health facilities had a PHO or a PHT and another member of staff and these were all government owned
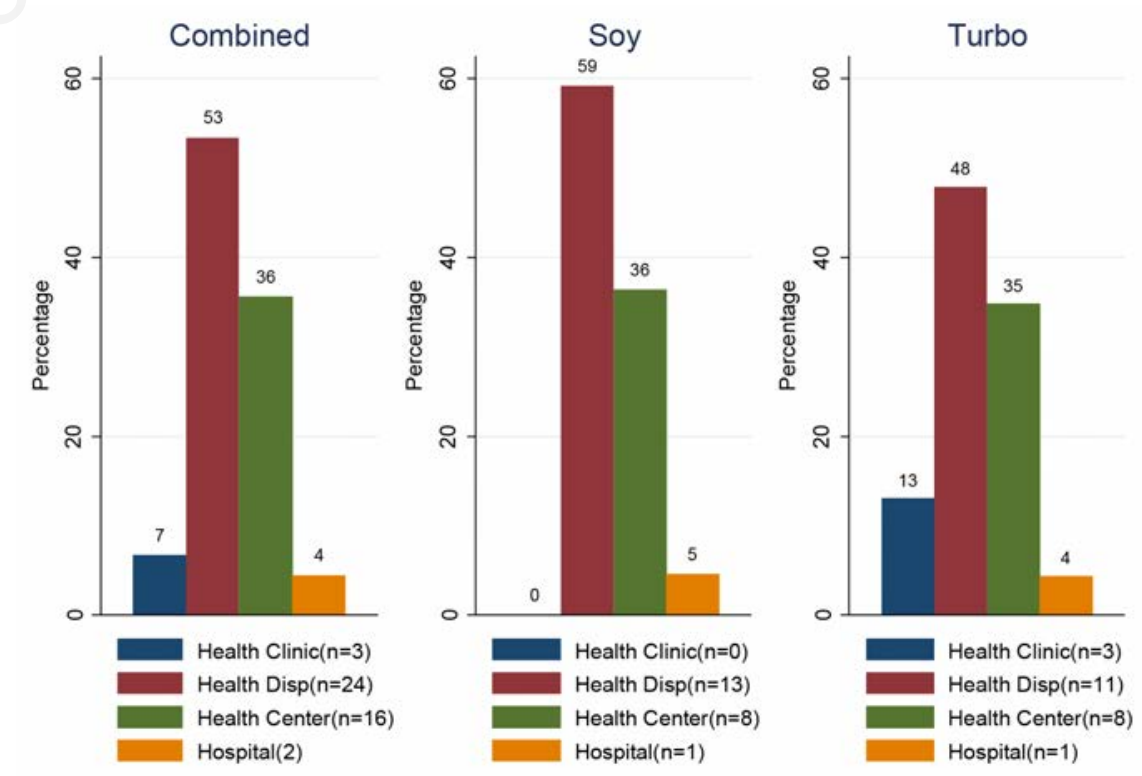

Figure 1. Overall distribution of the health facilities as well as distribution stratified by division. 
health facilities. The rest 11 (24\%) health facilities had no coordinators.

\section{Information on outbreak response to health personnel}

Twenty seven (63\%) health facilities did not provide information or training on outbreak response to their staff. A graphical presentation of those who offered the training is shown in Figure 4.

\section{Collection of information from the community on cases or deaths due to malaria and reporting in case of an epidemic}

Among the 22 health facilities with either a PHT or a PHO, 10 (40\%) health facilities collected information from the community on reports of suspected cases or deaths due to malaria on a monthly basis, 3 (12\%) health facilities did so on a weekly basis, 4 (16\%) did so twice a month and $3(12 \%)$ did not do it at all. The rest of the results are as shown in (Table 2). In the event that an epidemic was suspected it was reported within 24 hours in all the 22 health facilities with either a PHO or a PHT though there were no appropriate supplies for responding to a confirmed case or epidemic in all these health facilities.

\section{Reporting rate}

Overall the median reporting rate was 91.7 (IQR: 66.7-100\%). Government owned health facilities rate of reporting was high 100 (IQR: 83.3-100\%) compared to the private, mission or NGO based health facilities. Stratified by the division, the median reporting rate in Turbo was 83.3 (IQR: 41.7-100\%) and for Soy was 95.8 (IQR: $66.7-100 \%)$, these were reasonably high rates of reporting though the lower quartile for Turbo was below the 50\% mark. From Table 3 we realize that an average num-
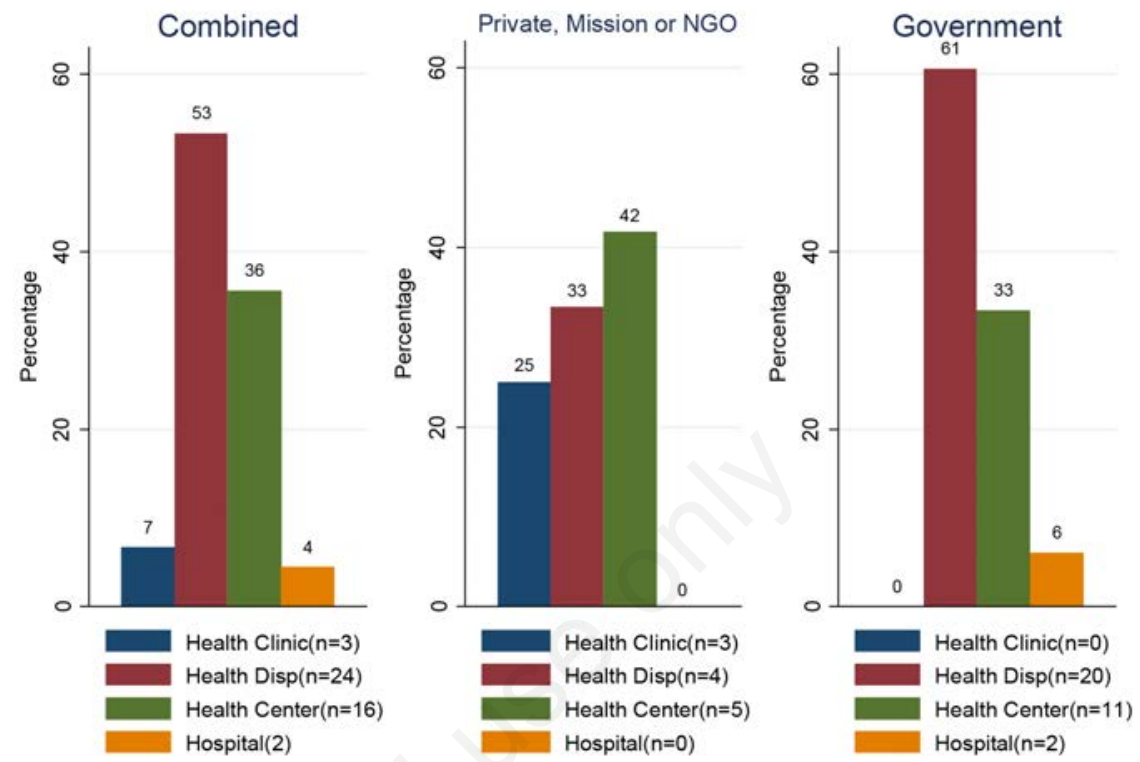

Figure 2. Distribution of the health facilities stratified by whether it is Government or Private, Mission or NGO health facilities.

Table 1. Use of standard case definition and plotting of trend lines.

\begin{tabular}{|c|c|c|c|c|c|c|}
\hline Characteristic & Levels & $\begin{array}{l}\text { Combined } \\
\mathrm{N}=45(\%)\end{array}$ & $\begin{array}{l}\text { Private, mission or NGO } \\
\qquad \mathrm{N}=12(\%)\end{array}$ & $\begin{array}{l}\text { Government } \\
\mathrm{N}=33(\%)\end{array}$ & $\begin{array}{c}\text { Soy } \\
\mathrm{N}=23(\%)\end{array}$ & $\begin{array}{c}\text { Turbo } \\
\mathrm{N}=22(\%)\end{array}$ \\
\hline $\begin{array}{l}\text { Are diagnoses of the cases of malaria } \\
\text { recorded in the clinic register according } \\
\text { to the standard case definition? }\end{array}$ & $\begin{array}{l}\text { Yes } \\
\text { No }\end{array}$ & $\begin{array}{c}45(100) \\
0\end{array}$ & $\begin{array}{c}12(100) \\
0\end{array}$ & $\begin{array}{c}33(100) \\
0\end{array}$ & $\begin{array}{c}23(100) \\
0\end{array}$ & $\begin{array}{c}22(100) \\
0\end{array}$ \\
\hline $\begin{array}{l}\text { Do health staffs use a standard case } \\
\text { definition to report the suspected } \\
\text { cases and outbreaks? }\end{array}$ & $\begin{array}{l}\text { Yes } \\
\text { No }\end{array}$ & $\begin{array}{c}45(100) \\
0\end{array}$ & $\begin{array}{c}12(100) \\
0\end{array}$ & $\begin{array}{c}33(100) \\
0\end{array}$ & $\begin{array}{c}23(100) \\
0\end{array}$ & $\begin{array}{c}22(100) \\
0\end{array}$ \\
\hline $\begin{array}{l}\text { Plotting trend lines for the numbers } \\
\text { of cases and deaths for each case } \\
\text { of malaria are }\end{array}$ & $\begin{array}{l}\text { Yes } \\
\text { No }\end{array}$ & $\begin{array}{l}15(33) \\
30(67)\end{array}$ & $\begin{array}{c}0 \\
12(100)\end{array}$ & $\begin{array}{l}15(47) \\
18(53)\end{array}$ & $\begin{array}{c}8(35) \\
15(65)\end{array}$ & $\begin{array}{c}7(32) \\
15(68)\end{array}$ \\
\hline Plotting the distribution of cases on a map & $\begin{array}{l}\text { Yes } \\
\text { No }\end{array}$ & $\begin{array}{c}4(9) \\
41(91)\end{array}$ & $\begin{array}{c}0 \\
12(100)\end{array}$ & $\begin{array}{c}4(12) \\
29(88)\end{array}$ & $\begin{array}{c}3(13) \\
20(87)\end{array}$ & $\begin{array}{c}1(5) \\
21(95)\end{array}$ \\
\hline
\end{tabular}

Table 2. Frequency of collection of information on suspected cases or deaths due to malaria.

\begin{tabular}{|c|c|c|c|c|c|}
\hline Frequency & $\begin{array}{l}\text { Combined } \\
\mathrm{N}=45(\%)\end{array}$ & $\begin{array}{l}\text { Private, mission or NGO } \\
\text { N=12 (\%) }\end{array}$ & $\begin{array}{l}\text { Government } \\
\mathrm{N}=33(\%)\end{array}$ & $\begin{array}{c}\text { Turbo } \\
\mathrm{N}=22(\%)\end{array}$ & $\begin{array}{c}\text { Soy } \\
\mathrm{N}=23(\%)\end{array}$ \\
\hline Not done & $23(12)$ & $12(100)$ & $11(8)$ & $11(8)$ & $12(15)$ \\
\hline Monthly & $10(40)$ & 0 & $10(42)$ & $7(58)$ & $3(23)$ \\
\hline Once in 3 months & $1(4)$ & 0 & $1(4)$ & $1(8)$ & 0 \\
\hline Once in two weeks & $2(8)$ & 0 & $2(8)$ & $1(8)$ & $1(8)$ \\
\hline Thrice a week & $1(4)$ & 0 & $1(4)$ & 0 & $1(8)$ \\
\hline Twice a month & $4(16)$ & 0 & $4(17)$ & $1(8)$ & $3(23)$ \\
\hline Twice a week & $1(4)$ & 0 & $1(4)$ & 0 & $1(8)$ \\
\hline Weekly & $3(12)$ & 0 & $3(13)$ & $1(8)$ & $2(15)$ \\
\hline Total & $45(100)$ & $12(100)$ & $33(100)$ & $22(100)$ & $23(100)$ \\
\hline
\end{tabular}


ber of 23 (51\%) health facilities had a high reporting of at least $90 \%$. This was also true for $20(61 \%)$ government facilities and Soy division where 14 (64\%) health facilities had a reporting rate of at least $90 \%$.

\section{Discussion}

\section{Malaria epidemic preparedness sys- tem}

In sub-Saharan Africa, malaria epidemics arise suddenly in mostly remote, disadvantaged settings without effective alert systems. Most of the research on malaria epidemic preparedness show that the existent systems are mainly concerned with the climatic-related factors such as; long-range forecasting, early warning and detection improving understanding of the role of temperature, rainfall, and $\mathrm{el}$ niño southern oscillation events and development of epidemic detection thresholds. ${ }^{8-11}$ Malaria epidemics evolve rapidly and most often occur in remote, under resourced settings without proper surveillance. Data on their evolution may thus go unrecorded, which prevents the development of evidence-based recommendations on effective epidemic control. The objective of early detection (or epidemiologic surveillance) is to monitor a disease continually so that abnormal events can be identified rapidly, in the expectation that intervention efforts can be initiated in a timely manner. ${ }^{12,13}$ Some of the early detection methods include slide positivity rate, epidemic thresholds and risk mapping. Epidemic thresholds show deviations in malaria morbidity patterns from the normal levels established over the years. Incidence of cases over and above the threshold should signify an outbreak and prompt for appropriate actions.

In Eldoret West District, only fifteen (35\%) health facilities plotted trend lines of the numbers of cases of malaria and this was quite alarming. For those health facilities that had PHO's, some of them reported that they had never heard or been told about plotting malaria thresholds and it was new knowledge to them, none of the private, mission and NGO facilities

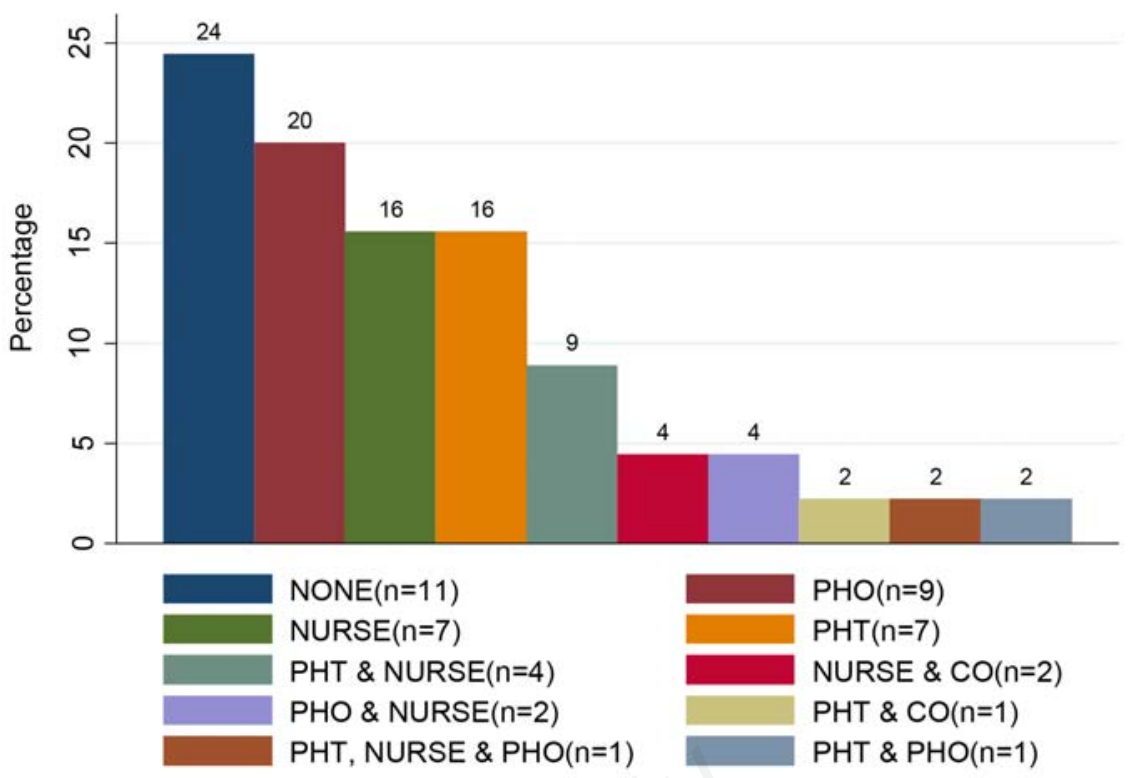

Figure 3. Outbreak coordinators for the health facility.

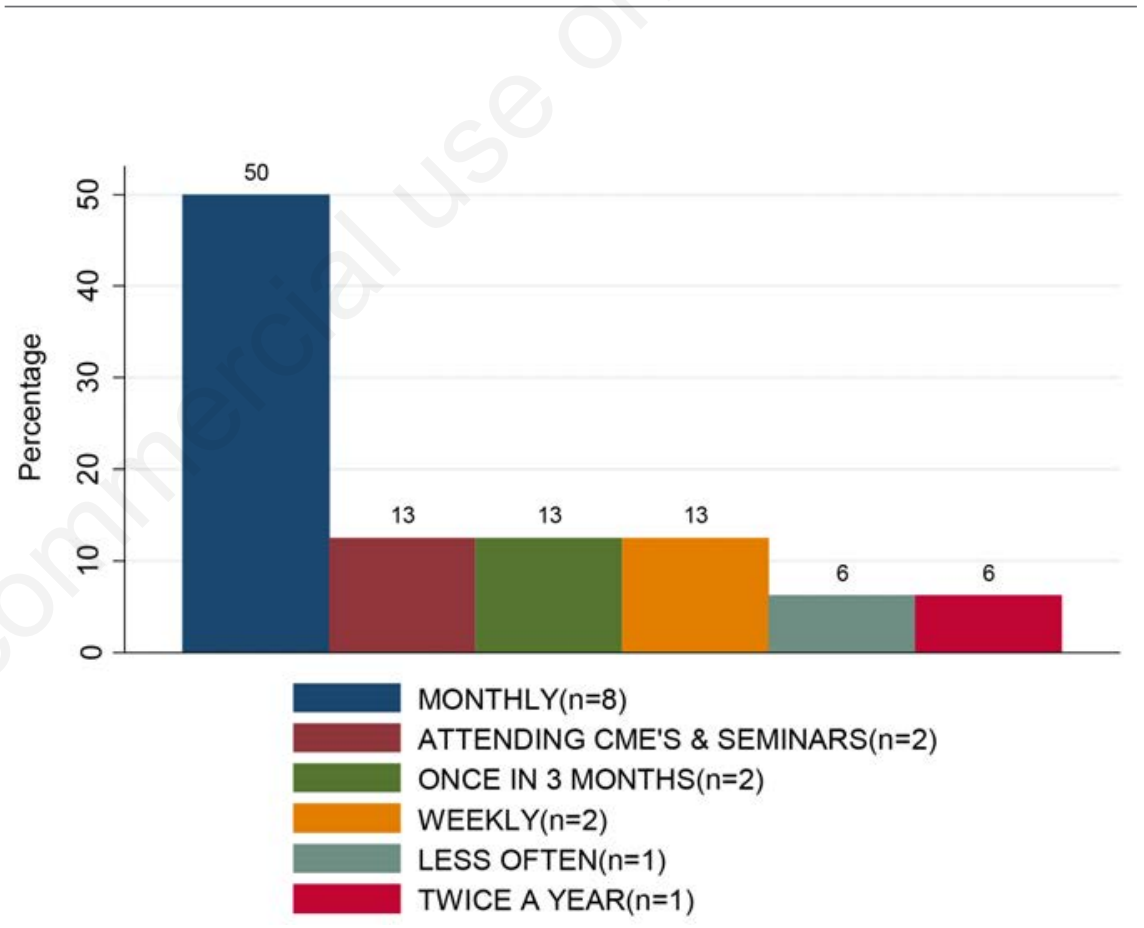

Figure 4. Frequency of training and information provision to the staff on outbreak response.

Table 3. Reporting system.

\begin{tabular}{|c|c|c|c|c|c|}
\hline $\begin{array}{l}\text { Reporting system } \\
\text { N=45 (\%) }\end{array}$ & $\begin{array}{l}\text { Combined } \\
\mathrm{N}=12(\%)\end{array}$ & $\begin{array}{l}\text { Private, mission or NGO } \\
\qquad N=33(\%)\end{array}$ & $\begin{array}{l}\text { Government } \\
\mathrm{N}=23(\%)\end{array}$ & $\begin{array}{c}\text { Soy } \\
\mathrm{N}=22(\%)\end{array}$ & Turbo \\
\hline Completeness & $91.7(66.7-100)$ & $45.8(12.5-83.3)$ & $100(83.3-100)$ & $95.8(66.7-100)$ & $83.3(41.7-100)$ \\
\hline $\begin{array}{l}\text { Completeness (categorized) } \\
<25 \% \\
25-50 \% \\
50-75 \% \\
75-95 \% \\
>95 \%\end{array}$ & $\begin{array}{l}5(11) \\
5(11) \\
7(16) \\
28(62) \\
18(40)\end{array}$ & $\begin{array}{l}4(33) \\
3(25) \\
2(17) \\
3(25) \\
1(8)\end{array}$ & $\begin{array}{l}1(3) \\
2(6) \\
5(15) \\
25(76) \\
17(52)\end{array}$ & $\begin{array}{l}1(4) \\
2(9) \\
4(17) \\
16(70) \\
11(50)\end{array}$ & $\begin{array}{l}4(18) \\
3(14) \\
3(13) \\
12(55) \\
7(30)\end{array}$ \\
\hline
\end{tabular}


plotted the cases of malaria on a graph. In some facilities the trend lines were not up to date and in some facilities the cases were last plotted five years ago. Some reported that they only send the weekly malaria reports but do not plot the trends. When malaria trends are not plotted, this could weaken the response capacities at the health facility and district level. A study done in Kenya, Burundi, Southern Sudan and Ethiopia showed that epidemics were detected after substantial delay and by agencies other than local authorities with unconventional methods, such as RDT (Random Diagnostic Test) monitoring among malnourished children, both preparedness and control, however, were seriously deficient. A recent review of epidemics in Africa has also revealed delays in both epidemic detection and response up to 20 weeks, basically, due to poor case reporting and analysis or low use of public facilities. According to a study in Iran, epidemic controls were deficient and epidemic lasted between 15-36 weeks. ${ }^{14}$

\section{Malaria risk maps}

The first step to epidemic surveillance is identifying areas that are epidemic prone, risk mapping predicts where environmental conditions are suitable for malaria epidemics, monitor other risks as well i.e. refugee camps, flooding, swamps etc. ${ }^{15}$ However, in Eldoret West District, only 4(9\%) health facilities plotted the distribution of the cases on a map. Just as in plotting malaria cases, most of the facilities visited reported that they were unaware of this strategy.

The existing malaria risk maps have limited operational use to support programmatic activities since they were produced at coarse spatial scales (at continental and country levels). They are largely based on expert opinion on climate based models and specific geo-referenced point prevalence data. ${ }^{16-22}$ 0ther attempts to produce similar risk maps are based on entomological parameters that are not fully validated..$^{23,24}$ None of the health facilities in the district plotted trend lines and maps for the number of deaths due to malaria. According to a study done by the Institute of Health Metrics and Evaluation at the University of Washington and published by The Lancet medical journal, it revealed that in many poor countries which lack medical infrastructure, mortality is often poorly probed or misidentified. ${ }^{9}$

\section{Supplies set aside for epidemic response and human resources}

Outbreaks and other public health emergencies require the rapid mobilization of resources such as vaccines, medicines and laboratory supplies. It is prudent to establish and preposition stockpiles of materials before an emergency occurs. As follow up to the public health risk assessment activity, districts should set up a contingency stock of drugs, vaccines, reagents and supplies to permit prompt management of the first cases without delay before support arrives from higher levels. Also regularly and carefully monitor the contingency stock in order to avoid shortages and expiry of drugs, vaccines, reagents and supplies. A commonly used rule is that $10-25 \%$ of the usual amount of supplies used in a regular season should be easily available for emergencies. Given the potential for large epidemics, it is suggested that $20-25 \%$ should be stockpiled. $^{25}$

In Eldoret West District, of the 45 health facilities 9 (20\%) had the supplies available or set aside for collecting laboratory specimens during an urgent situation. Most of the facilities reported that they bought supplies to be used for a particular time and did not consider the supplies for use during emergency situations. Most of the facilities reported that they were not aware that laboratory supplies should be set aside for use during emergency situations. A study done in Iran revealed that less than half of sampled health centers had at least one assigned small emergency site with adequate supply and equipment stock to be used in case of outbreaks. ${ }^{25}$

Thirty four (76\%) health facilities had a coordinator such as PHO, PHT, CO or Nurse. The rest 11 (24\%) health facilities had no coordinator. Most of the government owned facilities reported that the PHO or PHT were instrumental in outbreak coordination. Those facilities that did not have PHO or PHT utilized the PHO or PHT from the neighboring facilities. The private, mission and NGO facilities had no PHO or PHT and therefore they relied on the PHO or PHT from government health facilities. Epidemic preparedness must include a plan for quickly locating human resources (e.g., people to do blood surveys, mass drug administration and vector control) and field logistics. ${ }^{25}$

\section{Collection of information}

\section{on suspected cases or deaths due} to malaria and training on outbreak response

All the PHOs or PHTs in government facilities in Eldoret West District reported that they utilized Community Health Workers (CHWs) in collecting information from the community on the cases or deaths due to malaria. Private, mission and NGO did not collect information from the community since they had no PHO or PHT. The CHWs have a reporting tool which they use to collect information from the community and they record the cases or deaths due to malaria. The CHWs are supervised by the PHO called the Community Health Extension Workers (CHEWs) under the community strat- egy guidelines and they report back to them. ${ }^{26}$ CHWs have recently played an active role in malaria treatment and prevention activities in different countries. In Ethiopia, early diagnosis and treatment at the village level by CHWs was introduced in the early $1990 \mathrm{~s} .{ }^{27}$ This initiative is now accepted as an important means of intensifying malaria control in all malaria endemic areas of the country.

Twenty seven (63\%) health facilities did not provide any information or training on outbreak response to the staff of these facilities. Most of the facility in-charges reported that they had never given any training on outbreak response since they had never experienced a malaria epidemic in the recent years. District Health Management Team (DHMT) need to ensure that health staffs are equipped with the necessary information needed in carrying out an epidemic response.

\section{Malaria reporting system}

On a weekly basis, health workers report data from all health facilities (i.e. health posts and centers, district, province and central hospitals), which are supposed to alert managers of outbreaks identified through clinical timebased abnormal variation in the data. Most of the published cases have been focused to detect and treat the cases rather than to focus on reporting and circulation of information in surveillance systems. ${ }^{28-32}$

In the IDSR guideline, reporting rate is measured by timeliness and completeness. While timeliness of reports is vital for detecting and responding to epidemics, it was not evaluated here since the focus was on completeness of reporting whereby this was estimated by subtracting the total number of reports not received from the total number of reports expected divided by the total number of reports expected multiplied by $100 \%$. According to the IDSR guidelines, when the surveillance system is good, completeness rate should be approaching $100 \%$.

In Eldoret West District, the overall completeness of reporting rate was 91.7 (IQR: 66.7$100 \%$ ) implying that the surveillance system is good. Government owned health facilities rate of reporting was high 100 (IQR: 83.3-100\%) compared to the private, mission or NGO based health facilities that had a reporting rate of 45.8(IQR: 12.5-83.3\%). An average number of $23(51 \%)$ health facilities had a reporting rate of at least $90 \%$. However when the reporting was stratified, there were still some facilities that had a reporting rate of less than $50 \%$ and even $25 \%$. Only three out of twelve private and mission hospitals had a reporting rate of above 90\%. According to WHO World Malaria Report of 2012, on average reporting completeness in Kenya was at $100 \%$ (WHO, 2012). ${ }^{33}$ In Eldoret West District, sentinel sites reporting rate was at $100 \%$ and most government facilities had a 
high reporting rate of above $90 \%$, however private, mission and NGO facilities had low reporting rates hence pooling the overall reporting completeness rate to $91.7 \%$ and this was why the reporting completeness was slightly below the $100 \%$ rate found by the World Health Organization. Government health facilities had a reporting rate of $100 \%$ (83.3-100) which was consistent with the WHO survey.

According to HMIS survey carried out in Kenya, one of the weaknesses of the system was that the reporting rate was below $80 \% .{ }^{34}$ In Eldoret West District, 17 facilities had a reporting rate of below $80 \%$.Another issue found out was that since malaria reports were sent weekly, inconsistency especially in private and mission health facilities and some government facilities was a major problem. A study done in Mozambique on the analysis of the quality of routine data showed that in some health centers that cases were not being reported and later deliberately invented to cover the missing data. $^{35}$

\section{Conclusions}

In conclusion, all the health personnel used a standard case definition to register malaria suspected cases and outbreaks. However, only a small proportion (33\%) of the health facilities were observed to practice plotting of trend lines for the number cases and deaths of malaria. According to Integrated Disease Surveillance and Response guidelines, frequent plotting of trend lines for the number of cases of malaria is an important strategy towards epidemic preparedness.

Close to three quarters (76\%) of the health facilities had a designated malaria outbreak coordinator but on the other hand, a majority (63\%) of them did not provide information or training on malaria outbreak response to their health personnel. Most (40\%) of the health facilities collect information from the community on cases and deaths as a result of malaria on a monthly basis and the overall malaria reporting completeness rate was 91.7 (IQR: $66.7-100 \%$ ) implying that the malaria surveillance reporting system was good since the completeness rate was approaching $100 \%$ as recommended. We recommend that the Ministry of Health and Division of Malaria Control ensures improvement of malaria epidemic preparedness system in all health facilities with reference to epidemic detection i.e. frequent plotting of malaria trend lines and mapping of malaria cases and deaths. There is also need for health facility managers to ensure continuous professional training of their health personnel with information on malaria outbreak response strategies and stock their health facilities with adequate sup- plies for outbreak response.

\section{Limitation of the study}

The data collected was limited to the practices of health care workers and did not include follow up surveys and therefore it is unknown whether improvements in health care workers performance can lead to improved malaria surveillance and epidemic surveillance and response.

\section{References}

1. World Health Organization. Fact sheet: world malaria report; 2016. Available from: http://www.who.int/malaria/media/worldmalaria-report-2015/en/ Accessed: August 2016.

2. World Health Organization. Outline strategy for control of malaria in complex emergencies. WHO/CDS/RBM/2000.22; Geneva: WHO; 2000.

3. World Health Organization. Malaria epidemics: forecasting, prevention, early warning and control - From policy to practice. Geneva: WHO; 2004.

4. Division of Malaria Control Ministry of Public Health and Sanitation. national malaria strategy (2009-2017). 2009. Available from: http://www.nationalplanningcycles.org/sites/default/files/country_docs/Kenya/kenya_national_malaria_strategy_2009-2017.pdf

5. President's Malaria Initiative. Malaria operational plan. Kenya 2011. Available from: https://www.pmi.gov/docs/defaultsource/default-document-library/malariaoperational-plans/fy11/kenya_mopfyl1.pdf?sfvrsn=8

6. World Health Organization. World malaria report. Geneva, Switzerland; 2011.

7. Delacollette C, Stuyft Van der P, Molima K. Using community health workers for malaria control. Bull World Health Organ 1999;74:423-30.

8. Abeku TA, Hay SI, Ochola S, et al. Malaria epidemic early warning and detection in African highlands. Trends Parasitol 2004:20:400-5.

9. Hay S, Renshaw M, Ochola SA, et al. Performance of forecasting, warning and detection of malaria epidemics in the highlands of western Kenya. Trends Parasitol 2003;19:394-9.

10. Zhou G, Minakawa N, Githeko AK, Yan G. Climate variability and malaria epidemics in the highlands of East Africa. Trends Parasitol 2005;21:54-6.

11. Kovats RS, Bouma MJ, Hajat S, et al. El Niño and health. Lancet 2003;362:1481-9.

12. Eylenbosch WJ, Noah ND, eds. Surveillance in health and disease.
Oxford: Oxford University Press; 1988.

13. Thacker SB, Berkelman RL. Public health surveillance in the United States. Epidemiol Rev 1988;10:164-90.

14. Fox J, Balkan S, Tamrat A, et al. Malaria epidemics and interventions, Kenya, Burundi, Southern Sudan, and Ethiopia, 1999-2004. Emerg Infect Dis 2006;12:147785.

15. World Health Organization. Systems for the early detection of malaria epidemics in Africa. Geneva; WHO: 2006.

16. Schaller KF, Kuls W. Äthiopien: Eine geographis ch-medizin is che Landeskunde (Ethiopia: Geomedical Monograph). Springer-Verlag, Berlin; 1972.

17. Cox J, Craig M, Le Sueur D, Sharp B. Mapping malaria risk in the highlands of Africa. In: Mapping malaria risk in Africa/Highland malaria project (MARA/HIMAL). Technical Report, MARA/Durban. London: London School of Hygiene and Tropical Medicine; 1999.

18. Craig MH, Snow RW, Le Sueur D. A climate-based distribution model of malaria transmission in sub-Saharan Africa. Parasitol Today 1999;15:105.

19. Kleinschmidt I, Bagayoko M, Clarke GPY, et al. A spatial statistical approach to malaria mapping. Int J Epidemiol 2000; 29:355-61.

20. Omumbo JA, Hay SI, Snow RW, et al. Modeling malaria risk in East Africa at high-spatial resolution. Trop Med Int Health 2005;10:557-66.

21. Gemperli A, Vounatsou P, Sogoba N, Smith T. Malaria mapping using transmission models: applications to survey data from Mali. Am J Epidemiol 2006;163:289-97.

22. Kazembe LN, Kleinschmidt I, Holtz TH, Sharp BL. Spatial analysis and mapping of malaria risk in Malawi using point-referenced prevalence of infection data. Int $\mathrm{J}$ Health Geogr 2006;5:41.

23. Kiszewski AE. A global index representing the stability of malaria transmission. Am J Trop Med Hyg 2004;70:486-98.

24. Moffett A, Shackelford N, Sarkar S. Malaria in Africa: vector species' Niche models and relative risk maps. PLoS ONE 2007;2:824.

25. Ministry of Health Eritrea. Malaria epidemic forecasting and preparedness manual. 2003. Available from: http://pdf.usaid. gov/pdf_docs/Pnacu823.pdf

26. Ministry of Health Kenya. Reversing the trends: the second national health sector strategic plan of Kenya. 2006. Available from: http://www.healthyfutures.eu/ images/healthy/deliverables/D5.1/Kenya/k enya $\% 20$ second $\% 20$ national $\% 20$ health $\% 2$ 0sector\%20strategic $\% 20$ plan $\% 202005 \% 20$ \%202010.pdf 
27. Ghebreyesus TA, Witten KH, Getachew A, et al. The community-based malaria control programme in Tigray, northern Ethiopia. A review of programme set-up, activities, outcomes and impact. Parassitologia 2000;42:255-90.

28. Bjune G, Alene G. Diagnostic and treatment delay among pulmonary tuberculosis patients in Ethiopia: a cross sectional study. BMC Infect Dis 2005;5:112.

29. Bassili A, Seita A, Baghdadi S, et al. Diagnostic and treatment delay in tuberculosis in 7 countries of the Eastern Mediterranean region. Infect Dis Clin Pract 2008;16:23.

30. Rajeswari R, Chandrasekaran V, Suhadev
M, et al. Factors associated with patient and health system delays in the diagnosis of tuberculosis in South India. Intl $\mathbf{J}$ Tuberc Lung Dis 2002;6:789-95.

31. Chalumeau M, Holvoet L, Chéron G, et al. Delay in diagnosis of imported Plasmodium falciparum malaria in children. Eur J Clin Microbiol Infect Dis 2006;25:186-9.

32. Booth CM, MacLean JD. Knowledge, treatment-seeking, and socioeconomic impact of malaria on the Essequibo Coast of Guyana. MJM 2001;6:17-25.

33. World Health Organization. World malaria report. Geneva, WHO; 2012.

34. Ministry of Health Kenya. Health
Management Information System Strategic Plan 2009-2014. 2009. Available from: http://apps.who.int/ healthmetrics/library/countries/HMN_KE N_StrPlan_Final_2010_02_en.pdf

35. The EQUITY Project. Using information for action: a manual for health workers at facility level. 2001. Available from: http://www.uio.no/studier/emner/matnat/if i/INF5761/v12/undervisningsmateriale/He y w 00 d $\% 20$ a n d \% 20 R o h d e \% 20 \%20Using\%20information\%20for\%20actio n\%20a\%20manual\%20for\%20health\%20.p df. 